\title{
Incidence and survival for gastric and esophageal cancer diagnosed in British Columbia, 1990 to 1999
}

\author{
Morteza Bashash BSc MSc ${ }^{1}$, Amil Shah MDCM FRCPC FACP ${ }^{2,3}$, Greg Hislop BSc MSc MDCM ${ }^{1,4}$, \\ Angela Brooks-Wilson BSc MSc PhD ${ }^{5,6}$, Nhu Le BSc MSc PhD ${ }^{1,7}$, Chris Bajdik BSc MSc PhD ${ }^{1,5}$
}

\begin{abstract}
M Bashash, A Shah, G Hislop, A Brooks-Wilson, N Le, C Bajdik. Incidence and survival for gastric and esophageal cancer diagnosed in British Columbia, 1990 to 1999. Can J Gastroenterol 2008;22(2):143-148.
\end{abstract}

BACKGROUND: Geographical variation and temporal trends in the incidence of esophageal and gastric cancers vary according to both tumour morphology and organ subsite. Both diseases are among the deadliest forms of cancer. The incidence and survival rates for gastric and esophageal carcinoma in British Columbia (BC) between 1990 and 1999 are described.

METHODS: Incidence data for the period 1990 to 1999 were obtained from the BC Cancer Registry. Age-adjusted incidence and survival rates were computed by anatomical subsite, histological type and sex. All rates were standardized to the 1996 Canadian population. The estimated annual percentage change (EAPC) was used to measure incidence changes over time. Kaplan-Meier curves were used to show survival rates, and log-rank tests were used to test for differences in the curves among various groups.

RESULTS: Between 1990 and 1999, 1741 esophageal cancer cases and 3431 gastric cancer cases were registered in BC. There was an increase in the incidence of adenocarcinoma of the esophagus over time (EAPC $=9.6 \%$ ) among men, and of gastric cardia cancer among both women $(\mathrm{EAPC}=9.2 \%)$ and men $(\mathrm{EAPC}=3.8 \%)$. Patients with proximal gastric (cardia) cancer had significantly better survival rates than patients with cancer in the lower one-third of the esophagus. Among gastric cancers, patients with distal tumours had a significantly better survival rate than patients with proximal tumours.

DISCUSSION: The incidences of proximal gastric cancer and esophageal adenocarcinoma are increasing, and their survival patterns are different. Examining these cancers together may elucidate new etiological and prognostic factors.

Key Words: British Columbia; Epidemiology; Esophageal cancer; Gastric cancer; Incidence; Survival

\section{Cancers de l'estomac et de l'œsophage diagnostiqués en Colombie-Britannique, de 1990 à 1999 : incidence et survie}

CONTEXTE : Les tendances relatives aux variations géographiques et temporelles de l'incidence des cancers de l'estomac et de l'œesophage varient selon la morphologie des tumeurs et le sous-siège organique. Les deux maladies figurent parmi les formes les plus mortelles de cancer. Il sera donc question, dans le présent article, de l'incidence des cancers de l'estomac et de l'œsophage diagnostiqués en Colombie-Britannique (C.-B.), de 1990 à 1999, ainsi que du taux de survie.

MÉTHODE : Les données sur l'incidence, de 1990 à 1999, proviennent du BC Cancer Registry. Les taux d'incidence et de survie rectifiés selon l'âge ont été calculés en fonction du sous-siège anatomique, du type histologique et du sexe. Les taux ont tous été ramenés aux valeurs de 1996, au Canada. Nous avons utilisé l'estimation de la variation procentuelle annuelle (EVPA) pour mesurer les variations de l'incidence dans le temps, la courbe de Kaplan-Meier pour illustrer les taux de survie et le test de Mantel-Haenzel pour vérifier les écarts de courbes entre les différents groupes.

RÉSULTATS : Mille sept cent quarante et un cas de cancer de l'œesophage et 3431 cas de cancer de l'estomac ont été enregistrés en C.-B., de 1990 à 1999. Il y a eu une augmentation de l'incidence de l'adénocarcinome de l'œsophage (EVPA : 9,6\%) au fil du temps chez les hommes et du cancer du cardia gastrique tant chez les femmes (EVPA : 9,2\%) que chez les hommes (EVPA : 3,8 \%). Le taux de survie au cancer proximal de l'estomac (cardia) était sensiblement supérieur à celui enregistré pour le cancer du tiers inférieur de l'oesophage. En ce qui concerne le cancer de l'estomac, les patients atteints de tumeurs distales avaient un taux de survie significativement plus élevé que les patients atteints de tumeurs proximales.

DISCUSSION : L'incidence du cancer proximal de l'estomac et de l'adénocarcinome de l'œsophage est à la hausse, pourtant les taux de survie diffèrent. L'étude de ces deux types de cancer permettrait peut-être de découvrir de nouveaux facteurs étiologiques et pronostiques.
C hanging patterns of esophageal and gastric cancer incidences over recent decades have made them of increasing interest in cancer epidemiology. Geographical and temporal trends in incidence have been reported to vary according to both tumour morphology and organ subsite (1-3).

Esophageal cancer incidence shows a striking variation in different parts of the world (2,4). Approximately $80 \%$ of esophageal cancers occur in developing countries. Highincidence areas include parts of Asia, southeastern Africa, eastern South America and western Europe $(2,4)$. The incidence of esophageal cancer in North America is approximately five to 10 cases per 100,000 population, whereas it is more than 100 cases per 100,000 population in areas of the Caspian littoral of Iran (5). Before 1980, approximately $90 \%$ of all cases of esophageal cancers were squamous cell carcinomas (SCCs). Over the past two decades, however, the incidence of esophageal SCC has decreased, and that of adenocarcinoma has increased $(6,7)$. In many Western countries, adenocarcinoma is

${ }^{1}$ Cancer Control Research Program; ${ }^{2}$ Medical Oncology, BC Cancer Agency; ${ }^{3}$ Department of Medicine; ${ }^{4}$ Department of Health Care and

Epidemiology, University of British Columbia; ${ }^{5}$ Canada's Michael Smith Genome Sciences Centre; ${ }^{6}$ Department of Medical Genetics;

${ }^{7}$ Department of Statistics, University of British Columbia, Vancouver, British Columbia

Correspondence: Mr Morteza Bashash, Cancer Control Research Program, BC Cancer Agency, 2.111 - 675 West 10th Avenue, Vancouver,

British Columbia V5Z 1L3. Telephone 604-675-7059, fax 604-675-8180, e-mail mbashash@bccrc.ca

Received for publication June 14, 2007. Accepted December 4, 2007 


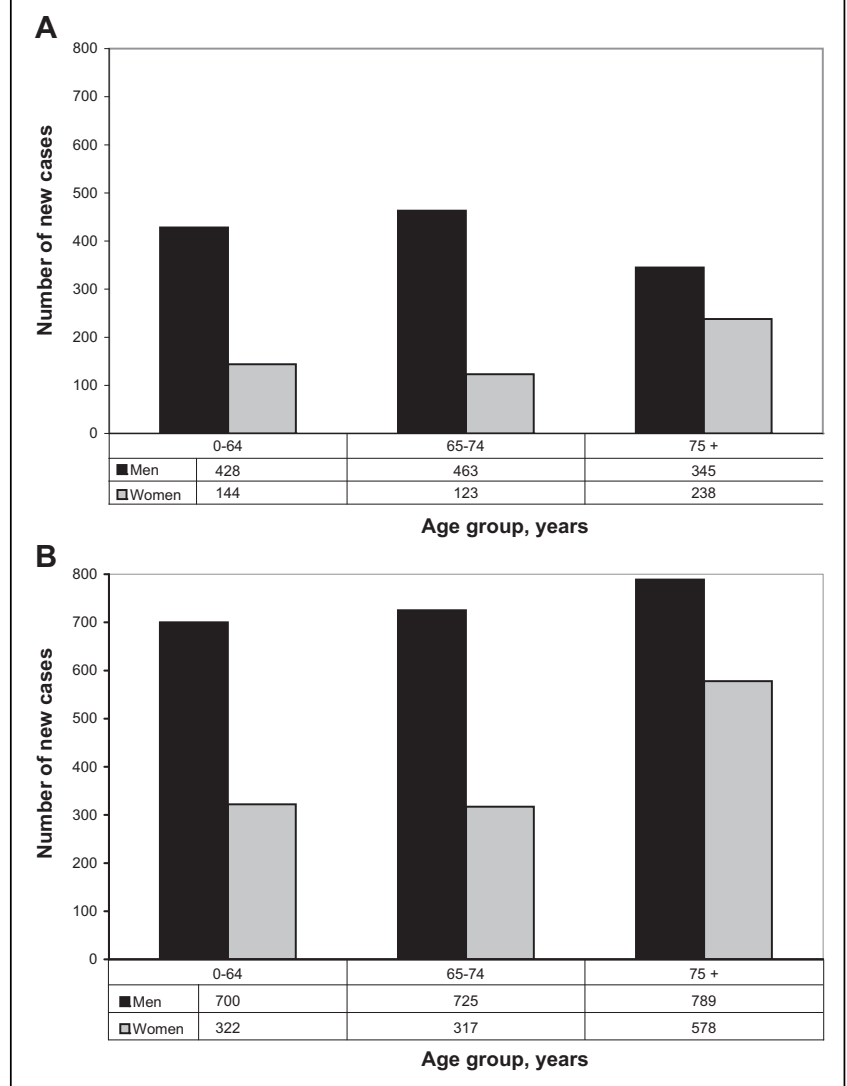

Figure 1) New diagnoses of esophageal (A) and gastric (B) cancer in British Columbia during 1990 to 1999 by age and sex

now more common than SCC (8). Esophageal cancer is one of the deadliest types of cancers and the sixth leading cause of death from cancer worldwide (9).

Gastric cancer incidence and mortality rates have fallen dramatically over the past 70 years $(1,10)$. Nonetheless, gastric cancer remains the fourth most commonly diagnosed cancer, and the second most common cause of cancer-related death worldwide $(1,10)$. Adenocarcinoma is the most common histological type of gastric cancer, accounting for $90 \%$ to $95 \%$ of all gastric malignancies $(1,4,11)$. Despite a decline in the incidence of distal gastric cancers, the incidence of proximal tumours has been increasing since the 1970s, especially among men in Western countries (12). Tumours of the gastric cardia now account for nearly one-half of all gastric cancers among men in the United States (US) and the United Kingdom (13). Gastric cancer is a disease of poor prognosis and high mortality (14). In general, countries with higher incidence rates of gastric cancer show better survival rates than countries with lower incidence rates (14).

In the present paper, we describe the incidence and survival rates for gastric and esophageal cancers in the population of British Columbia (BC) between 1990 and 1999.

\section{METHODS}

\section{Data}

Cancer incidence data for invasive primary esophageal and gastric cancers were obtained from the BC Cancer Registry for the period from 1990 to 1999 . The topography and histology of cases were coded according to the International
Classification of Diseases for Oncology, Second Edition (ICD-O-2) (15). The topography of esophageal cancers was grouped into four anatomical subsites: esophagus, upper one-third (ICD-O-2, C15.0 to C15.3); esophagus, middle one-third (ICD-O-2, C15.4); esophagus, lower one-third (ICD-O-2, C15.5); and overlapping lesion and esophagus unknown (ICD-O-2, C15.8 and C15.9). The topography of gastric cancer was grouped into three subsites: proximal (cardia) in the gastroesophageal junction or upper one-third of the stomach (ICD-O-2, C16.0 to C16.1); distal stomach or lower two-thirds of the stomach (ICD-O-2, C16.2 to C16.7); and unknown or unspecified/overlapping regions (ICD-O-2, C16.8 to C16.9). Histological categories for esophageal and gastric cancers were SCC (ICD-O-2, 8050 to 8082), adenocarcinoma (ICD-O-2, 8140 to 8573 ) and other (mainly ICD-O-2, 8000 to 8020 ) (16). Diffuse gastric tumours were defined by ICD-O-2 histology codes 8142,8145 and 8490 (16). Five years of follow-up information was available for each patient. The stage of diagnosis was defined according to the American Joint Committee on Cancer's tumour-node-metastasis classification (17).

\section{Statistical analysis}

Annual age-adjusted incidence rates were computed by anatomical subsite, histological type and sex. All rates were standardized to the 1996 Canadian population. The estimated annual percentage change (EAPC) was used to measure trends or the change in rates over time by fitting a regression line to the natural logarithm of the rates, using calendar year as an independent variable (18). Overall survival was calculated as the time between cancer diagnosis and death. Cases diagnosed at the time of a patient's death were excluded, because they were probably registered through autopsy or death certificate only. Survival curves were calculated using the Kaplan-Meier method, and log-rank statistics were used to compare survival differences between groups. $\mathrm{P}<0.05$ was considered to be statistically significant.

\section{Incidence}

\section{RESULTS}

Between 1990 and 1999, 1741 cases of esophageal cancer and 3431 cases of gastric cancer were diagnosed in BC. Figure 1 shows the frequency of esophageal and gastric cancers according to the age at diagnosis and sex. The mean \pm SD age at diagnosis was $69.0 \pm 11.5$ years for esophageal cancer and $69.5 \pm 13.2$ years for gastric cancer. For both esophageal and gastric cancers, men were more commonly affected, with $71.0 \%$ and $64.5 \%$ of diagnoses, respectively. Staging information for $60 \%(n=1132)$ of esophageal and $20 \%(n=696)$ of gastric cancer patients was available. For esophageal cancer, $10 \%$ of patients had stage I, $56 \%$ had stage II, $11 \%$ had stage III and 23\% had stage IV disease. For gastric cancer, $14 \%$ of patients had stage I, 16\% had stage II, 23\% had stage III (18\% IIIa, 5\% IIIb) and 47\% had stage IV disease.

Table 1 shows the incidence rates for gastric and esophageal cancers by topography, histology and sex. For esophageal cancer, $55 \%$ were diagnosed in the lower one-third, $22 \%$ in the middle one-third, and $10.5 \%$ in the upper one-third. The incidence of men with cancers in the lower esophagus increased during the study period $(\mathrm{EAPC}=4.6 \%$, with an average incidence of 3.7 cases per 100,000 population). Fifty-seven per cent of esophageal cancers were SCCs, $43 \%$ were adenocarcinomas and $12 \%$ were other histological types. There was a 
TABLE 1

Age standardized incidence rate per 100,000 population (ASR) and estimated annual percentage change (EAPC), with $95 \%$ Cls, for esophageal and gastric cancers, by topology and histology in British Columbia, 1990 to 1999

\begin{tabular}{lccccc}
\hline & \multicolumn{2}{c}{ Men } & & \multicolumn{2}{c}{ Women } \\
\cline { 2 - 3 } \cline { 5 - 6 } $\begin{array}{l}\text { Cancer } \\
\text { type }\end{array}$ & $\begin{array}{c}\text { ASR } \\
(95 \% \mathrm{Cl})\end{array}$ & $\begin{array}{c}\text { EAPC } \\
(95 \% \mathrm{Cl}), \%\end{array}$ & & $\begin{array}{c}\text { ASR } \\
(95 \% \mathrm{Cl})\end{array}$ & $\begin{array}{c}\text { EAPC } \\
(95 \% \mathrm{Cl}), \%\end{array}$ \\
\hline
\end{tabular}

Esophageal (topology)

$\begin{array}{lllll}\text { Upper } & 0.6(0.5-0.7) & -1.2(-8.8-7.1) & 0.4(0.3-0.4) & 6.0(-1.5-14.1)\end{array}$

Middle $\quad 1.3(1.1-1.5) \quad 0.4(-5-6.1) \quad 0.5(0.5,0.6) \quad-1.9(-6.1-2.5)$

Lower $\quad 3.7(3.3-4.1) \quad 4.6(1.1-8.3) \quad 0.7(0.7,0.8) \quad 0.1(-4.6-5.1)$

Gastric (topology)

\begin{tabular}{lllll}
\hline Cardia & $4.4(4-4.8)$ & $3.8(0.3-7.4)$ & $1.0(0.8-1.2)$ & $9.2(2.6-16.2)$ \\
Distal & $3.8(3.6-4)$ & $0.4(-1.9-2.7)$ & $2.2(2-2.4)$ & $-1.8(-6-2)$
\end{tabular}

Esophageal (histology)

\begin{tabular}{lllll}
\hline SCC & $2.9(2.6-3.2)$ & $-2.9(-6.6-1)$ & $1.7(1.6-1.8)$ & $0.4(-2.8-3.7)$ \\
AC & $3.3(2.7-3.9)$ & $9.5(5.1-14.2)$ & $0.2(0.2-0.3)$ & $6.7(-4.9-19.7)$
\end{tabular}

Gastric (histology)

AC diffuse $\quad 1.6(1.3-1.9) \quad 7.5(1-14.4) \quad 1.3(1.1-1.5) \quad 8.1(2.5-14)$

AC (other) $\quad 9.1(8.6-9.5) \quad-0.3(-2.3-1.8) \quad 2.9(2.6-3.2) \quad-2.7(-6-1)$

AC Adenocarcinoma; SCC Squamous cell carcinoma

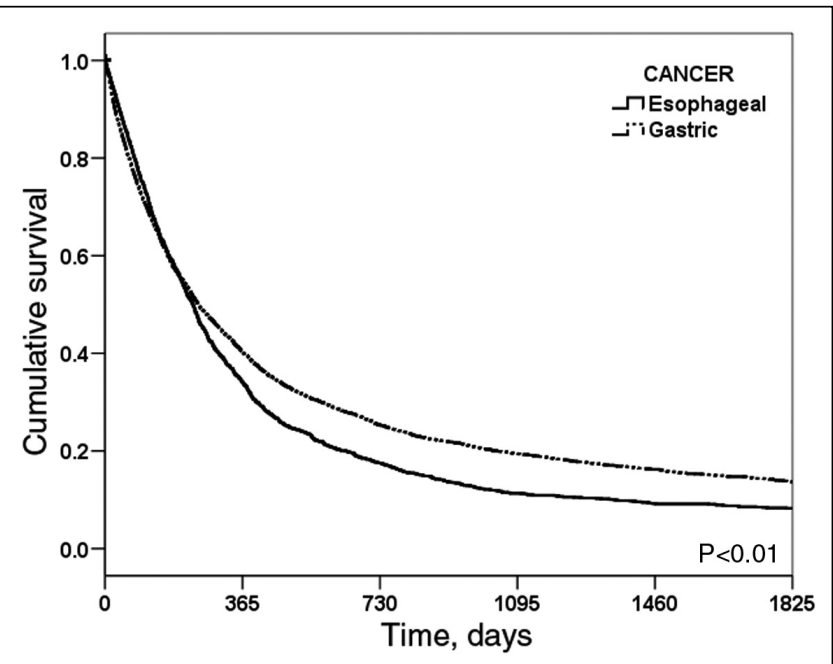

Figure 2) Five-year survival curves for patients with esophageal and gastric cancers

substantial increase in the incidence of esophageal adenocarcinoma over the study period among men (EAPC $=9.5 \%$, with an average incidence of 3.3 cases per 100,000 population). There was a lower increase in esophageal adenocarcinoma incidence among women (EAPC $=6.7 \%$, with an average incidence of 0.2 cases per 100,000 population). For gastric cancer, $29 \%$ of cases were diagnosed in the proximal one-third and $33 \%$ in the distal two-thirds, and 38\% had an unspecified topology. There was an increase in the incidence of proximal (cardia) gastric cancers over time for both men (EAPC $=3.8 \%$, with an average incidence of 4.4 cases per 100,000 population) and women $(\mathrm{EAPC}=9.2 \%$, with an average incidence of 1.0 case per 100,000 population). Eighty-four per cent of gastric cancer patients were diagnosed with adenocarcinoma, and 16\% were diagnosed with other histological types. Among gastric

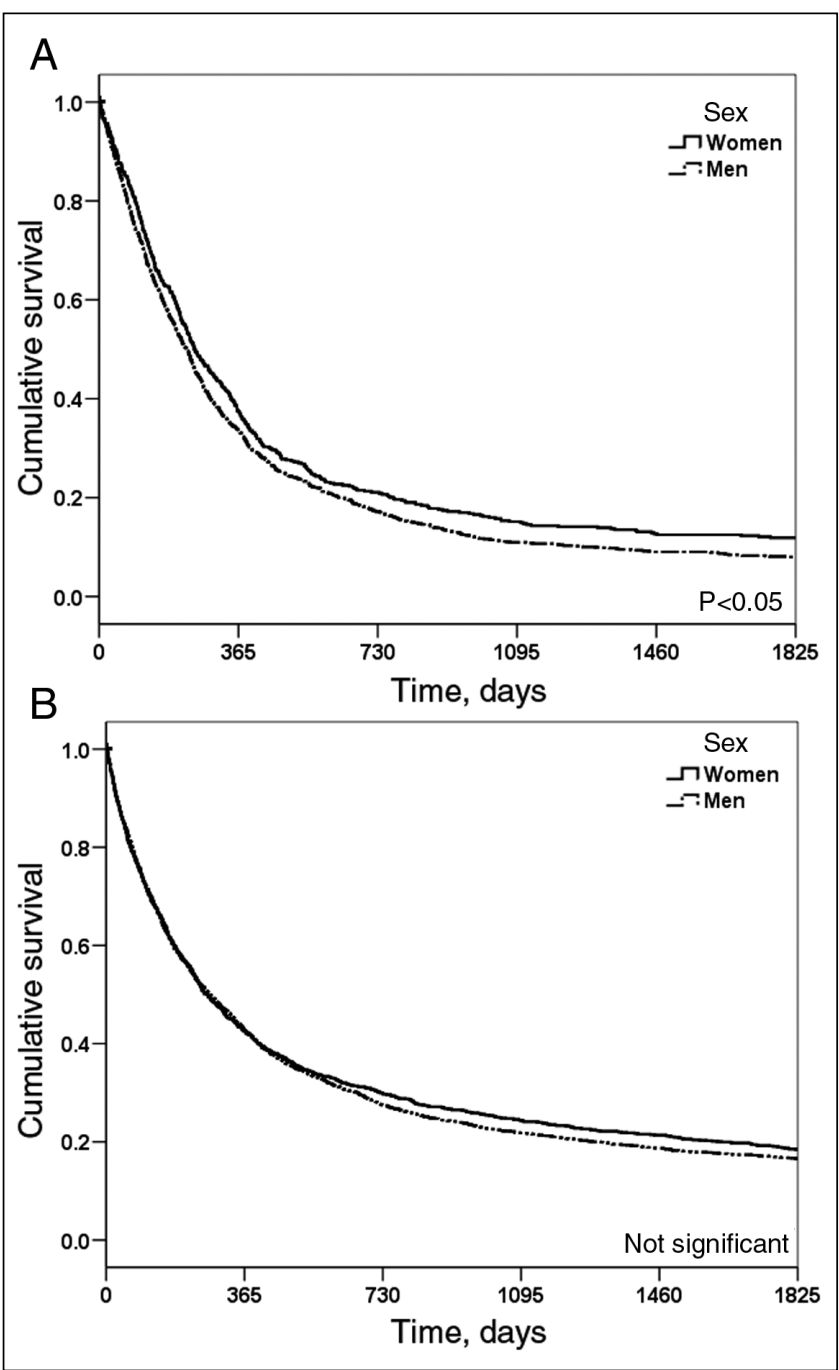

Figure 3) Five-year survival curves by sex for patients with esophageal (A) and gastric (B) cancers

adenocarcinomas, 20\% were the diffuse type (including signet ring cell carcinoma). The rates of diffuse gastric cancer in both men $(\mathrm{EAPC}=7.5 \%$, with an average incidence of 1.6 cases per 100,000 population) and women (EAPC $=8.1$, with an average incidence of 1.3 cases per 100,000 population) increased substantially from 1990 to 1999 .

\section{Survival}

Figure 2 shows the overall five-year survival curves for patients with esophageal and gastric cancer. The patients had overall five-year survival rates of $8.8 \%$ for esophageal cancer and $16.2 \%$ for gastric cancer; the survival rate of patients with gastric cancer was significantly better than for those with esophageal cancer. Sex did not have any significant effect on the survival of patients with gastric cancer, but for esophageal cancer, women had significantly better survival rates than men (Figure 3). There was no significant difference in survival rates for patients with cancers affecting the lower, middle and upper one-thirds of the esophagus; however, patients with cancer of the upper onethird had a slightly better survival rate than patients who had cancer in the lower one-third (Figure 4A). For gastric cancer, patients with distal tumours had a significantly better survival rate than those with proximal tumours $(\mathrm{P}<0.001)$ (Figure 4B); 


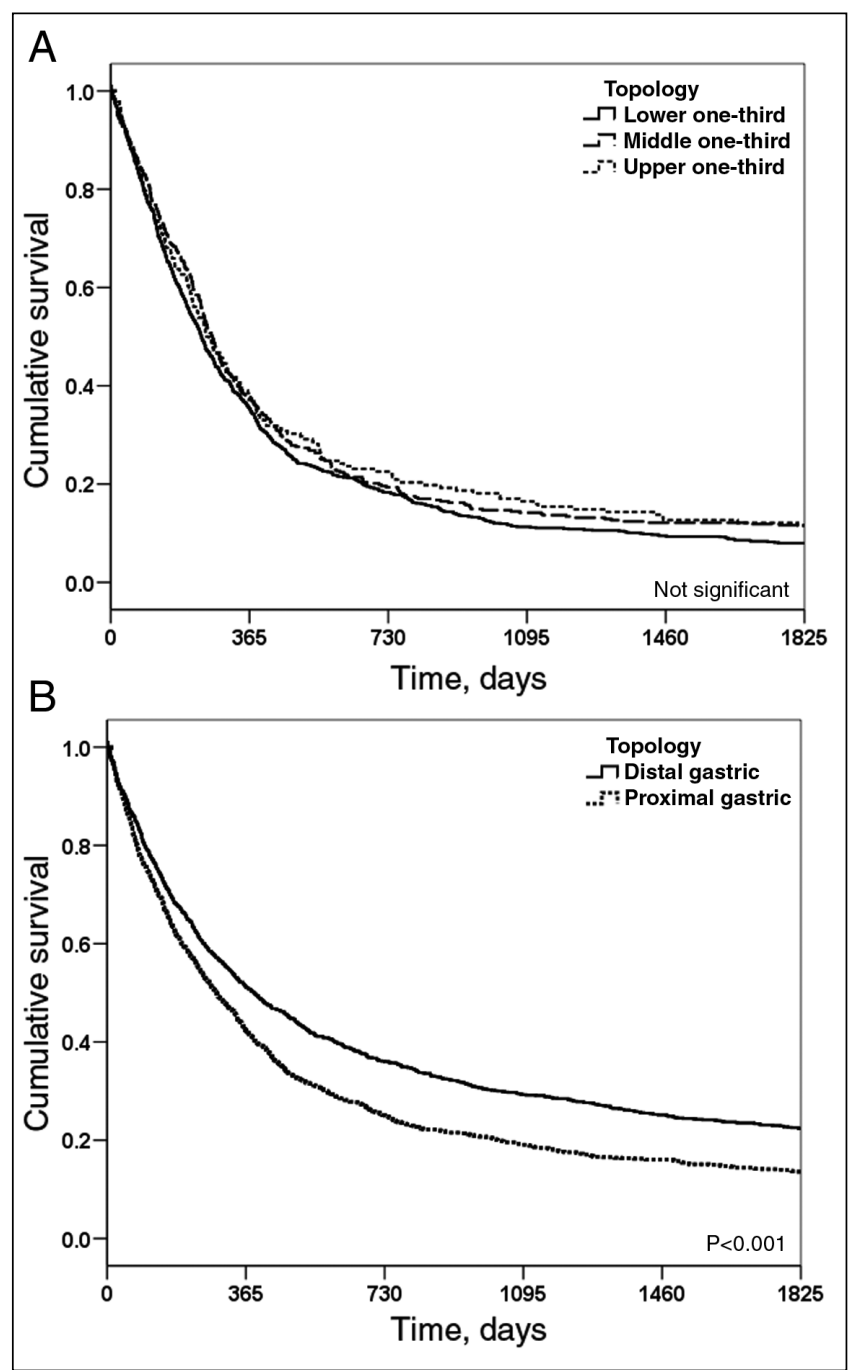

Figure 4) Five-year survival curves by tumour location for patients with esophageal (A) and gastric (B) cancer

however, patients with proximal gastric (cardia) cancers had significantly better survival rates than those with adenocarcinoma tumours in the lower one-third of the esophagus $(\mathrm{P}<0.001)$. There were no significant differences in terms of tumour histology in the survival rate of patients with esophageal cancer.

\section{DISCUSSION}

Over the past decades, the epidemiology of upper gastrointestinal (GI) cancers has changed. In the present study, we found some similarities and interesting differences between changing patterns of cancers in the gastroesophageal junction area. The most notable similarity was the incidence of proximal gastric cancer and esophageal adenocarcinoma. Major differences between these cancers were seen in the survival rates of patients and the incidence classified by sex. Over the study period, an increased incidence of esophageal adenocarcinoma was only substantial in men, but women had a greater increase in incidence than men of proximal gastric cancer. This trend is different than noted in other parts of Canada (19).

The incidence of esophageal cancer in men showed an increase over the study period. The pattern of histological changes for esophageal cancer in $\mathrm{BC}$ is compatible with patterns in other Western countries. The incidence of esophageal adenocarcinoma in men is rising in most countries, although this trend is highly varied among ethnicities (19-21). Our study did not analyze ethnicity, because the $\mathrm{BC}$ registry does not collect this information. The highest incidence rates for white men in the year 2000 were found in Great Britain (5.0 to 8.7 cases per 100,000 population) and Australia ( 4.8 cases per 100,000 population), followed by the Netherlands (4.4 cases per 100,000 population), the US (3.7 cases per 100,000 population) and Denmark (2.8 cases per 100,000 population) (21). Regional differences in esophageal adenocarcinoma incidence rates have been reported in the US (22). BC has shown a decrease in the incidence of esophageal SCCs; however, this decrease was not significant and was different from the trend in Ontario (23).

Gastric cancer incidence has decreased over the past several decades worldwide (4). In 1900, gastric cancer was the leading cause of death in the US (24). The incidence of distal gastric cancer in $\mathrm{BC}$ has been almost steady over time; however, the incidence of proximal (cardia) cancer has increased. The increasing incidence rate of proximal gastric cancer in men follows an increasing trend in Ontario (23). Like adenocarcinoma of the esophagus, the incidence of gastric cardia cancer has increased significantly since the 1970s (25). In the US, this increasing trend has stabilized since the late 1980s (26). Our study indicates that the incidence and the increase in incidence of proximal gastric cancer is higher in $\mathrm{BC}$ than in the US and Ontario. Unlike other major tumours of the upper GI tract, incidence of diffuse gastric cancer was not influenced by sex in BC. The incidence of diffuse gastric cancer in the US increased from 0.3 cases per 100,000 population in 1973 to 1.8 cases per 100,000 population in 2000 (16).

The five-year overall survival rate for patients with esophageal cancer in $\mathrm{BC}(9 \%)$ is very poor. In our study, women had a better esophageal cancer survival rate than men. This result agrees with a report from Europe (27). We remind readers that rates in the present paper should be compared with caution with those in other reports because of the possible effect of standardizing with a different population. Topology in esophageal cancer patients did not significantly influence survival. However, cancer in the upper esophagus has a small survival benefit compared with cancer in the lower esophagus, possibly because they are detected or present earlier. According to our data, there was no significant difference in survival rates between patients with SCC and those with adenocarcinoma of the esophagus. These results are in contrast with studies in the United Kingdom (1987 to 2000) and Germany (1982 to 2000), which showed that adenocarcinoma has a more favourable prognosis than SCC $(28,29)$ in esophageal cancer patients. In general, gastric cancer five-year survival $(16 \%)$ was poor, but it was significantly better than that for esophageal cancer. This is a slightly better survival than previously reported in gastric cancer patients treated in BC between 1978 and 1997 (30). In our study, a significant difference in five-year survival was observed between distal and proximal cancers of the stomach, with a worse outcome noted in patients with cancer of the cardia. This agrees with previous studies, which have shown the same prognosis pattern for cardia cancers as with other gastric cancers $(31,32)$.

The strength of the present study was the availability of population-based data with details of histology and pathology. Furthermore, the Gastrointestinal Tumour Group at the BC 
Cancer Agency provides province-wide treatment guidelines in $\mathrm{BC}$ so that most patients receive similar treatment. This is important, because treatment is one of the greatest determinants of cancer patients' survival. Over the study period, the general treatment for esophageal cancer was surgery in stage I cancer; preoperative radiation (4500 cGy in 25 fractions) and chemotherapy (5-fluorouracil [5-FU] plus cisplatin) followed by surgery and further chemotherapy (5-FU plus cisplatin) in $50 \%$ of stage II and III cancers, or surgery followed by radiation (4500 cGy in 25 fractions) and chemotherapy (5-FU plus cisplatin) for the other $50 \%$; and chemotherapy (5-FU plus cisplatin) in $75 \%$ of stage IV cancers, with the remainder receiving symptomatic care only. The general treatment for resectable gastric cancer (stages I, II or III) was surgery; chemotherapy with 5-FU or 5-FU plus cisplatin was prescribed for approximately $65 \%$ of stage IV patients, while the rest had symptomatic care only.

Weaknessess of the present study were the number of cases with unspecified histology and pathology, and the lack of ethnicity information.

Although gastric and esophageal cancers are relatively infrequent in Canada, their epidemiology is changing. The trends are most evident when tumours are classified by histology and anatomical location. While the incidences of SCC of the esophagus and adenocarcinoma of the distal stomach appear to be stable or decreasing, the incidences of esophageal adenocarcinoma and gastric cardia cancer are increasing. We offer three possible explanations for this trend: increased exposure to one or more risk factors; misclassification and overdiagnosis; and immigration and the changing population of BC. Risk factors for gastric cancer include Helicobacter pylori infection (33); heredity, genetic and immunological variables (11); diet and lifestyle (34); tobacco smoking (35); obesity (36); ionizing radiation (37); and exposure to the Epstein-Barr virus (38). Risk factors for esophageal cancer include gastroesophageal reflux (39), Barrett's esophagus (40), asthma medication use, lower esophageal sphincter-relaxing medication use (41), cholecystectomy (42), obesity (36) and cigarette smoking (25). It is unlikely that misclassification or overdiagnosis is responsible for the temporal changes, because all of the cancers were invasive, and different survival patterns between cardia and esophageal adenocarcinoma indicate that these are separate diseases. Finally, the number of immigrants living in BC in the 1996 Census of Canada was 903,190 (43). This is a $25 \%$ increase since 1991 (43). Among these, immigrants from China were the largest ethnic group represented $-14 \%$ of the BC population. Esophageal SCCs and distal gastric cancers are more common in China, but there is no indication of an increase in the incidence rate of cardia or lower esophagus adenocarcinomas.

Tumours in the upper GI tract are heterogeneous, while they share some epidemiological features. Gastric and esophageal cancers arise in advanced age, predominantly occur in men, are silent until advanced stages and therefore have very poor survival rates. Gastric cardia cancers share epidemiological features with adenocarcinomas of the lower esophagus and gastroesophageal junction. Both gastric and esophageal cancer patients have poor survival rates. Factors associated with the poor survival rates are the absence of symptoms in early cancer, a lack of effective screening tools and a lack of effective treatment options. Examining these cancers together may elucidate new etiological and prognostic factors.

ACKNOWLEDGEMENTS: Morteza Bashash is the recipient of a Trainee Award from the Michael Smith Foundation for Health Research and the BC Cancer Foundation. Angela Brooks-Wilson and Chris Bajdik are recipients of Senior Scholar Awards from the Michael Smith Foundation for Health Research. The authors acknowledge the BC Cancer Registry for data, and Drs Isabella Tai, Chen Zhu and Christian Kollmansberger for their help in interpreting the findings.

This study was completed at the BC Cancer Agency.

\section{REFERENCES}

1. Shibata DK, Parsonnet J. Stomach cancer. In: Schottenfeld D, Fraumeni JF Jr, eds. Cancer Epidemiology and Prevention, 3rd edn. New York: Oxford University Press, 2006:707-20.

2. Blot WJ, McLaughlin JK, Fraumeni JF Jr. Esophageal cancer. In: Schottenfeld D, Fraumeni JF Jr, eds. Cancer Epidemiology and Prevention, 3rd edn. New York: Oxford University Press, 2006:697-706.

3. Hansen S, Wiig JN, Giercksky KE, Tretli S. Esophageal and gastric carcinoma in Norway 1958-1992: Incidence time trend variability according to morphological subtypes and organ subsites. Int J Cancer 1997;71:340-4.

4. Hamilton S, Aaltonen LA. World Health Organization Classification of Tumours: Pathology and Genetics of Tumours of the Digestive System, 1st edn. Lyon: International Agency for Research on Cancer, 2000.

5. Allen JW, Richardson JD, Edwards MJ. Squamous cell carcinoma of the esophagus: A review and update. Surg Oncol 1997;6:193-200.

6. Powell J, McConkey CC, Gillison EW, Spychal RT. Continuing rising trend in oesophageal adenocarcinoma. Int J Cancer 20021;102:422-7. (Erratum in 2003;104:798).

7. Patel M, Ferry K, Franceschi D, Kaklamanos I, Livingstone A, Ardalan B. Esophageal carcinoma: Current controversial topics. Cancer Invest 2004:22:897-912.

8. Gerson LB, Triadafilopoulos G. Screening for esophageal adenocarcinoma: An evidence-based approach. Am J Med 2002;113:499-505.

9. Enzinger PC, Mayer RJ. Esophageal cancer. N Engl J Med 2003;349:2241-52.

10. Parkin DM, Bray F, Ferlay J, Pisani P. Global cancer statistics, 2002. CA Cancer J Clin 2005;55:74-108.

11. Shang J, Pena AS. Multidisciplinary approach to understand the pathogenesis of gastric cancer. World J Gastroenterol 2005;11:4131-9.

12. Blot WJ, Devesa SS, Kneller RW, Fraumeni JF Jr. Rising incidence of adenocarcinoma of the esophagus and gastric cardia. JAMA 1991;265:1287-9.

13. Brown LM, Devesa SS. Epidemiologic trends in esophageal and gastric cancer in the United States. Surg Oncol Clin N Am 2002;11:235-56.

14. Crew KD, Neugut AI. Epidemiology of gastric cancer. World J Gastroenterol 2006;12:354-62.

15. Percy C, Van Holten B, Muir C. International Classification of Diseases for Oncology, 2nd edn. Geneva: World Health Organization, 1990.

16. Henson DE, Dittus C, Younes M, Nguyen H, Albores-Saavedra J. Differential trends in the intestinal and diffuse types of gastric carcinoma in the United States, 1973-2000: Increase in the signet ring cell type. Arch Pathol Lab Med 2004;128:765-70.

17. American Joint Committee on Cancer. Manual for Staging of Cancer, 4th edn. Philadelphia: JB Lippincott Company, 1992.

18. Kleinbaum DG, Kupper LL, Muller KE. Applied Regression Analysis and Other Multivariable Methods. Boston: PWSKENT Publishing Company, 1998.

19. Kubo A, Corley DA. Marked multi-ethnic variation of esophageal and gastric cardia carcinomas within the United States. Am J Gastroenterol 2004;99:582-8. 
20. Devesa SS, Blot WJ, Fraumeni JF Jr. Changing patterns in the incidence of esophageal and gastric carcinoma in the United States. Cancer 1998;83:2049-53.

21. Bollschweiler E, Wolfgarten E, Gutschow C, Holscher AH. Demographic variations in the rising incidence of esophageal adenocarcinoma in white males. Cancer 2001;92:549-55.

22. Kubo A, Corley DA. Marked regional variation in adenocarcinomas of the esophagus and the gastric cardia in the United States. Cancer 2002;95:2096-102.

23. Parfitt JR, Miladinovic Z, Driman DK. Increasing incidence of adenocarcinoma of the gastroesophageal junction and distal stomach in Canada - an epidemiological study from 1964-2002. Can J Gastroenterol 2006;20:271-6.

24. Breslow L, Cumberland WG. Progress and objectives in cancer control. JAMA 1988;259:1690-4.

25. DeMeester SR. Adenocarcinoma of the esophagus and cardia: A review of the disease and its treatment. Ann Surg Oncol 2006;13:12-30.

26. El-Serag HB, Mason AC, Petersen N, Key CR. Epidemiological differences between adenocarcinoma of the oesophagus and adenocarcinoma of the gastric cardia in the USA. Gut 2002;50:368-72.

27. Micheli A, Mariotto A, Giorgi Rossi A, Gatta G, Muti P. The prognostic role of gender in survival of adult cancer patients. EUROCARE Working Group. Eur J Cancer 1998;34(14):2271-8.

28. Siewert JR, Stein HJ, Feith M, Bruecher BL, Bartels H, Fink U. Histologic tumor type is an independent prognostic parameter in esophageal cancer: Lessons from more than 1,000 consecutive resections at a single center in the Western world. Ann Surg 2001;234:360-7.

29. Alexiou C, Khan OA, Black E, et al. Survival after esophageal resection for carcinoma: The importance of the histologic cell type. Ann Thorac Surg 2006;82:1073-7.

30. Gill S, Shah A, Le N, Cook EF, Yoshida EM. Asian ethnicityrelated differences in gastric cancer presentation and outcome among patients treated at a Canadian cancer center. J Clin Oncol 2003;21:2070-6.

31. Saito H, Fukumoto Y, Osaki T, et al. Distinct recurrence pattern and outcome of adenocarcinoma of the gastric cardia in comparison with carcinoma of other regions of the stomach. World J Surg 2006;30:1864-9.
32. Ohno S, Tomisaki S, Oiwa H, et al. Clinicopathologic characteristics and outcome of adenocarcinoma of the human gastric cardia in comparison with carcinoma of other regions of the stomach. J Am Coll Surg 1995;180:577-82.

33. Parsonnet J, Friedman GD, Vandersteen DP, et al. Helicobacter pylori infection and the risk of gastric carcinoma. N Engl J Med 1991;325:1127-31

34. Kono S, Hirohata T. Nutrition and stomach cancer. Cancer Causes Control 1996;7:41-55.

35. Gonzalez CA, Pera G, Agudo A, et al. Smoking and the risk of gastric cancer in the European Prospective Investigation Into Cancer and Nutrition (EPIC). Int J Cancer 2003;107:629-34.

36. Chow WH, Blot WJ, Vaughan TL, et al. Body mass index and risk of adenocarcinomas of the esophagus and gastric cardia. J Natl Cancer Inst 1998;90:150-5.

37. Thompson DE, Mabuchi K, Ron E, et al. Cancer incidence in atomic bomb survivors. Part II: Solid tumors, 1958-1987. Radiat Res 1994;137(2 Suppl):S17-67. (Erratum in 1994;139:129).

38. Levine PH, Stemmermann G, Lennette ET, Hildesheim A, Shibata D, Nomura A. Elevated antibody titers to Epstein-Barr virus prior to the diagnosis of Epstein-Barr-virus-associated gastric adenocarcinoma. Int J Cancer 1995;60:642-4.

39. Lagergren J, Bergstrom R, Lindgren A, Nyren O. Symptomatic gastroesophageal reflux as a risk factor for esophageal adenocarcinoma. N Engl J Med 1999;340:825-31.

40. Solaymani-Dodaran M, Logan RF, West J, Card T, Coupland C. Risk of oesophageal cancer in Barrett's oesophagus and gastrooesophageal reflux. Gut 2004;53:1070-4.

41. Vaughan TL, Farrow DC, Hansten PD, et al. Risk of esophageal and gastric adenocarcinomas in relation to use of calcium channel blockers, asthma drugs, and other medications that promote gastroesophageal reflux. Cancer Epidemiol Biomarkers Prev 1998;7:749-56.

42. Freedman J, Ye W, Naslund E, Lagergren J. Association between cholecystectomy and adenocarcinoma of the esophagus. Gastroenterology 2001;121:548-53.

43. Statistics Canada. The 1996 Census Profile of British Columbia. $<$ http://www.bcstats.gov.bc.ca/data/cen96/bc96cen.pdf> (Version current at January 17, 2008). 


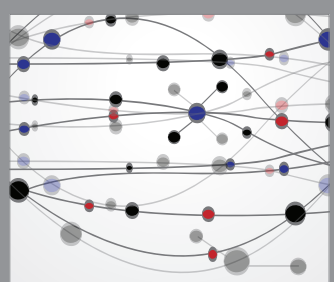

The Scientific World Journal
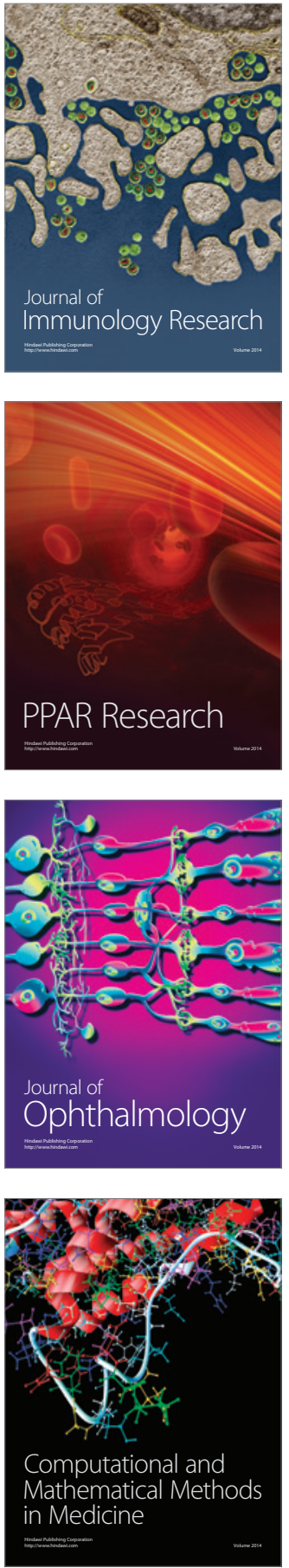

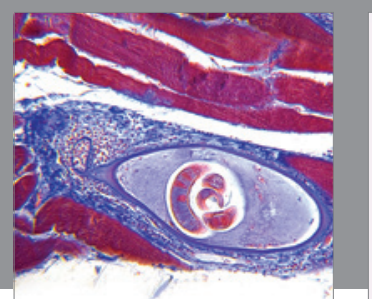

Gastroenterology Research and Practice

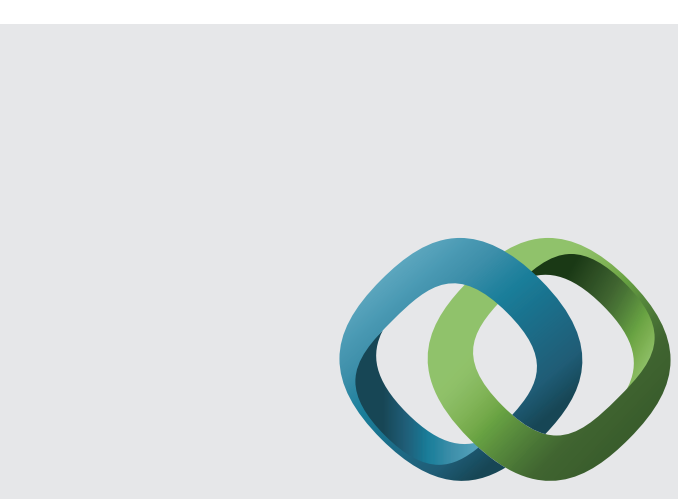

\section{Hindawi}

Submit your manuscripts at

http://www.hindawi.com
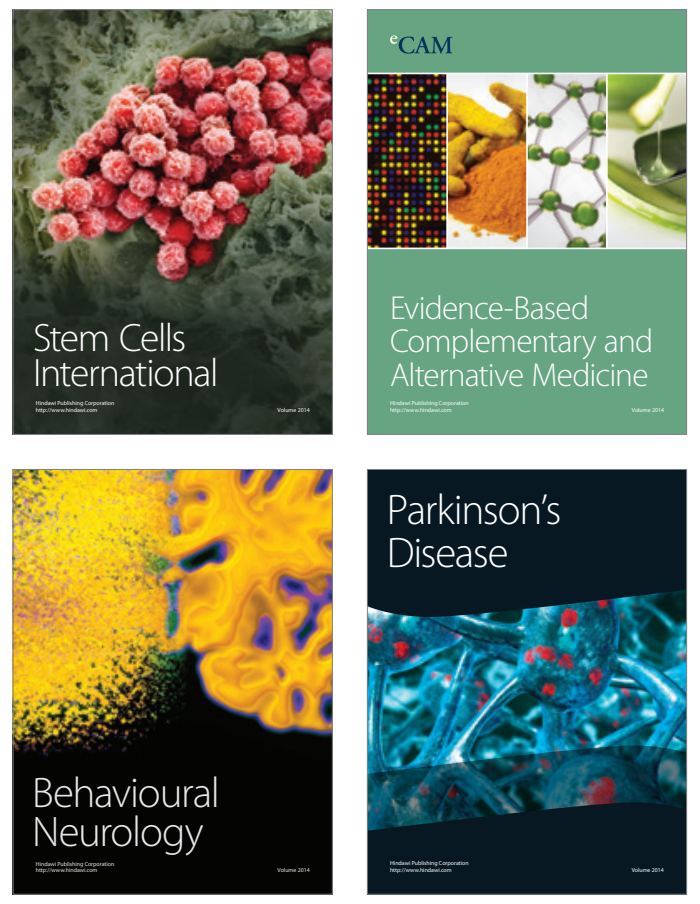
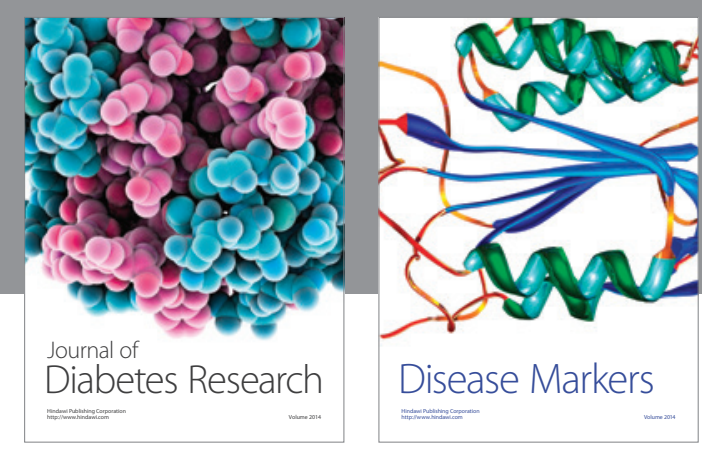

Disease Markers
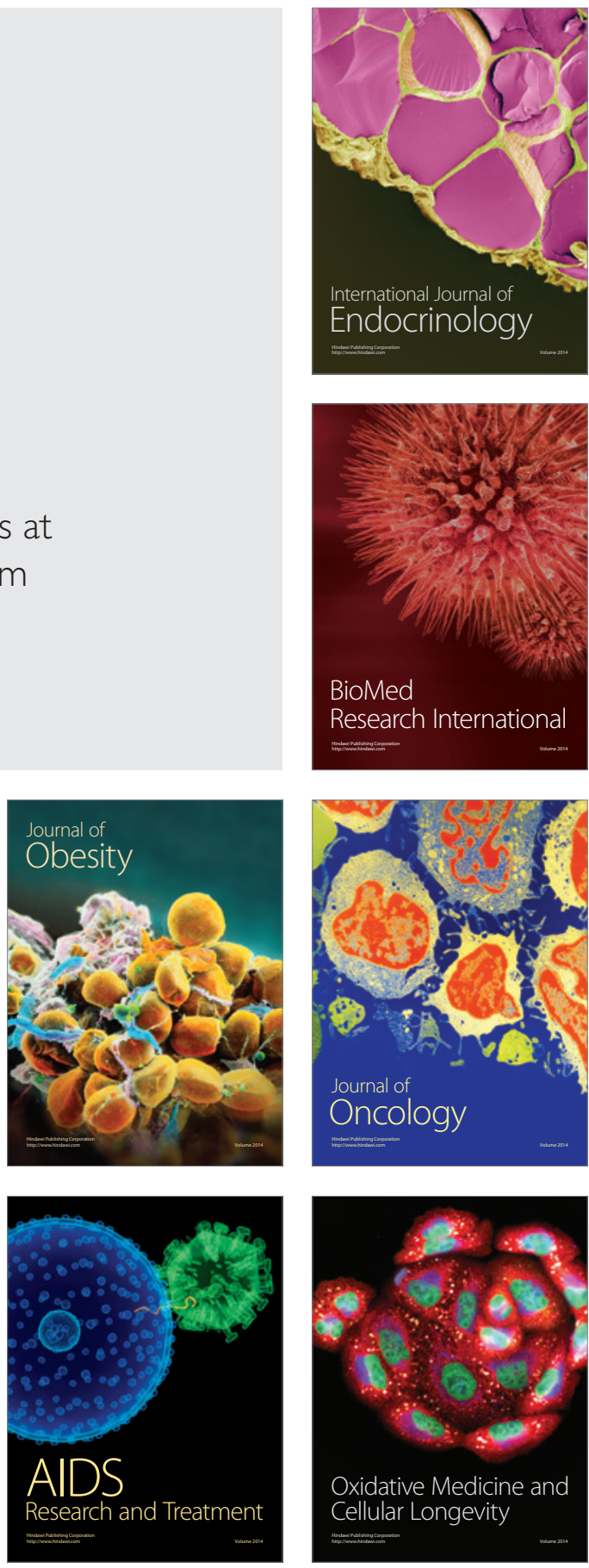